\title{
miR-3677-5p promotes the proliferation, migration and invasion of hepatocellular carcinoma cells and is associated with prognosis
}

\author{
HAI-XIANG MAO, BAI-WEN CHEN, JIE WANG, CHEN-YANG MA, YI-CHAO GAN and KAI-JIE QIU \\ Department of Pancreatic and Hepatobiliary Surgery, Ningbo Medical Treatment Center, \\ Lihuili Hospital, Ningbo, Zhejiang 315000, P.R. China
}

Received July 5, 2020; Accepted January 28, 2021

DOI: $10.3892 /$ etm.2021.10212

\begin{abstract}
MicroRNA (miRNA/miR)-3677 has been indicated to be negatively associated with the survival of patients with hepatocellular carcinoma (HCC) based on The Cancer Genome Atlas database. However, as a novel miRNA, the role of miR-3677-5p in $\mathrm{HCC}$ has remained to be elucidated. In the present study, the expression of miR-3677-5p was assessed in HCC tissues and cell lines using reverse transcription-quantitative PCR. Survival analysis was performed using Kaplan-Meier curves. Furthermore, the prognostic significance of miR-3677-5p was evaluated using Cox regression analysis. The effects of miR-3677-5p on cell proliferation, as well as migration and invasion capacities, were analyzed using Cell Counting Kit-8, crystal violet and Transwell assays. The results demonstrated that the level of miR-3677-5p expression was upregulated in human HCC tissues and cell lines and that miR-3677-5p expression was closely associated with tumor size, TNM stage and vascular invasion. Furthermore, high miR-3677-5p expression was significantly associated with unfavorable clinical prognosis for patients with HCC. Overexpression of miR-3677-5p was indicated to significantly promote the proliferation, migration and invasion of HCC cells, whereas knockdown of miR-3677-5p was observed to have an inhibitory effect. In conclusion, the present study demonstrated that miR-3677-5p acts as an oncogene that has a critical role in the regulation of HCC proliferation and progression. Hence, miR-3677-5p may serve as a valuable prognostic biomarker and may be developed as a promising therapeutic target for HCC.
\end{abstract}

Correspondence to: Dr Kai-Jie Qiu, Department of Pancreatic and Hepatobiliary Surgery, Ningbo Medical Treatment Center, Lihuili Hospital, 57 Xingning Road, Yin'zhou, Ningbo, Zhejiang 315000, P.R. China

E-mail: kaijiedr@163.com

Key words: microRNA-3677-5p, hepatocellular carcinoma, progression, prognosis

\section{Introduction}

With high morbidity and mortality rates, hepatocellular carcinoma (HCC) is the fifth most commonly diagnosed cancer type and the third leading cause of cancer-associated mortality worldwide (1). Multiple treatment interventions, such as liver resection, transarterial chemoembolization, radiotherapy and chemotherapy with sorafenib, have been used to treat HCC. However, the prognosis of patients with HCC remains poor due to difficulties making a prognosis, high recurrence and early vascular invasion $(2,3)$. As a type of cancer, HCC is associated with multi-gene mutations (4). Molecular targeting is currently used as a novel therapy for advanced HCC, as it has been indicated to acquire favorable curative effects that significantly prolong the survival time of patients (5). Thus, the obtainment of a detailed understanding of HCC development and identification of novel molecular targets for $\mathrm{HCC}$ treatment have become a significant research focus. In particular, the discovery of reliable biological markers for the diagnosis, treatment and prognosis of $\mathrm{HCC}$ is required.

MicroRNAs (miRNAs/miRs) are endogenous small non-coding RNAs with a length of 19-25 nucleotides. The expression of various miRNAs and their functions in tumor progression have been extensively elucidated. Abnormal expression of miRNAs has been indicated to regulate cellular processes such as cell proliferation, differentiation, development and apoptosis in multiple cancer types (6-8). Furthermore, an increasing number of studies have demonstrated the diagnostic, prognostic and biological functions of miRNAs in patients with HCC (9-11).

Several studies have reported that the expression of miR-3677 is negatively associated with the survival of patients with HCC and that miR-3677 is one of the tumor-specific miRNAs in HCC (12-15). In addition, the preliminary prognostic role of miR-3677 has been determined in colon cancer $(16,17)$. As a novel miRNA, miR-3677-5p has not been previously reported in neoplasms, to the best of our knowledge. In particular, the prognostic and biological roles of miR-3677-5p in HCC have remained elusive.

In the present study, the prognostic value and biological functions of miR-3677-5p in HCC and its involvement in HCC progression were explored. It was determined that miR-3677-5p was upregulated in human primary HCC tissues and cell lines. Furthermore, high expression of miR-3677-5p 
was revealed to be associated with unfavorable prognosis of patients with HCC. In addition, in vitro functional assays demonstrated that miR-3677-5p has a role in promoting the proliferation, migration and invasion of HCC cells.

\section{Materials and methods}

Clinical samples. A total of 80 patients with HCC from the Ningbo Medical Treatment Center Li Huili Hospital (Ningbo, China) between January 2013 and January 2016 were enrolled in the present study. With HCC being pathologically confirmed, all patients underwent routine surgery without receiving any pre-surgical anticancer treatments, such as chemotherapy or radiotherapy. All HCC tissues and their adjacent normal liver tissues were collected and then immediately frozen in liquid nitrogen for further analyses. Clinicopathological information and survival information were recorded during follow-ups. To determine tumor recurrence, regular physical examinations were performed for all patients. Overall survival (OS) was defined as the time interval from the date of surgery to the date of death or the last follow-up. Recurrence-free survival (RFS) was defined as the time interval from the date of surgery to the date of death, recurrence or the last follow-up. The follow-up data in this present study was censored in December 2019. All patients included provided written informed consent. The present study was approved by the ethics committee of the Ningbo Medical Treatment Center Li Huili Hospital (Ningbo, China) and was performed in accordance with the Declaration of Helsinki.

Cell culture. The human HCC cell lines Hep3B, LM3 and MHCC-97H and the cell line transformed human liver epithelial-2 (THLE-2) were obtained from the Cell Bank of the Type Culture Collection of the Chinese Academy of Sciences. HCC cells were cultured in DMEM (Gibco; Thermo Fisher Scientific, Inc.) supplemented with $10 \%$ fetal bovine serum (FBS; Gibco; Thermo Fisher Scientific, Inc.), $100 \mathrm{U} / \mathrm{ml}$ penicillin and $100 \mathrm{~g} / \mathrm{ml}$ streptomycin (Sangong Biotech, Inc.) at $37^{\circ} \mathrm{C}$ in a humidified atmosphere containing $5 \% \mathrm{CO}_{2}$.

RNA extraction and reverse transcription-quantitative $(R T-q) P C R$. Total RNA samples from clinical tissues and cell lines were extracted using TRIzol $^{\circledR}$ reagent (Invitrogen; Thermo Fisher Scientific, Inc.). The RNA concentration was determined using a BioDrop (Biochrom Ltd). RT was performed using the PrimeScript ${ }^{\mathrm{TM}}$ RT reagent kit (Takara Bio Inc.) in accordance with the manufacturer's protocol, following which qPCR was performed using a SYBR Green I Mastermix (cat. no. SY1020; Beijing Solarbio Science \& Technology Co., Ltd.) on an ABI PRISM 7500 Sequence Detection System (Applied Biosystems; Thermo Fisher Scientific, Inc.) using the following thermocycling conditions: Initial denaturation at $95^{\circ} \mathrm{C}$ for $4 \mathrm{~min}$, followed by 40 cycles of $95^{\circ} \mathrm{C}$ for $15 \mathrm{sec}, 60^{\circ} \mathrm{C}$ for $30 \mathrm{sec}$ and $72^{\circ} \mathrm{C}$ for $30 \mathrm{sec}$, final extension at $72^{\circ} \mathrm{C}$ for $2 \mathrm{~min}$ and a hold at $4^{\circ} \mathrm{C}$. The relative expression of miR-3677-5p was normalized to that of U6 using the $2^{-\Delta \Delta C q}$ method (18). All oligonucleotides used for RT-qPCR were synthesized by RiboBio. The primer sequences used were as follows: miR-3677-5p forward, 5'-GGG GTACCCCCTGGCTGGAACAGAAGAT-3' and reverse, 5'-CCCAAGCTTCCCTGGTCTTGGCTGGGATC-3' and U6 forward, 5'-CGCTTCGGCAGCACATATAC-3' and reverse, 5'-TTCACGAATTTGCGTGTCATC-3'.

Cell transfection. miR-3677-5p mimics, miR-3677-5p inhibitor and their corresponding negative controls (NCs) were purchased from Shanghai GenePharma Co., Ltd. HCC cells were seeded into six-well plates at a density of $5 \times 10^{5}$ cells per well and cultured for $24 \mathrm{~h}$ prior to transfection using Lipofectamine ${ }^{\circledR} 2000$ (Invitrogen; Thermo Fisher Scientific, Inc.) in accordance with the manufacturer's protocol. After transfection for $48 \mathrm{~h}$, the cells were used in subsequent experiments. The primer sequences used were as follows: miR-3677-5p mimics, 5'-UGUUUGGUGUCACACGAC GAC-3' and its NC, 5'-UUCUCCGAACGUGUCACGUTT-3'; miR-3677-5p inhibitor, 5'-UCACAAGUUAGGGUCUCA GGG-3' and its NC, 5'-UUCUCCGAACGUGUCACGUGG C-3'.

Cell Counting Kit-8 (CCK-8) assay. Transfected HCC cells were seeded into 96 -well plates at a density of $5 \times 10^{3}$ cells in $100 \mu 1$ culture medium per well. A total of three replicates were set up for each experimental condition. Following culture for $24,48,72$ or $96 \mathrm{~h}, 10 \mu \mathrm{l}$ CCK-8 solution (Dojindo Molecular Technologies, Inc.) was added to the medium and the cells were then incubated at $37^{\circ} \mathrm{C}$ for another $2 \mathrm{~h}$. Optical density (OD) values were measured at $450 \mathrm{~nm}$ using an automatic microplate reader (Bio-Rad Laboratories, Inc.).

Crystal violet assay. Transfected HCC cells were seeded into six-well plates at a density of 1,000 cells per well and then cultured in DMEM medium with 10\% FBS. The culture medium was changed every 3 days for 2 weeks at $37^{\circ} \mathrm{C}$ in a humidified atmosphere containing $5 \% \mathrm{CO}_{2}$. Following removal of the medium, cells were stained with crystal violet ( $1 \mathrm{ml} 0.5 \%$ crystal violet solution in $10 \%$ formalin) for $10 \mathrm{~min}$ at room temperature. Subsequently, these fixed cells were washed with PBS and images were acquired. The OD was measured at $570 \mathrm{~nm}$ using an automatic microplate reader (Bio-Rad Laboratories, Inc.).

Transwell assays. The migratory and invasive ability of transfected HCC cells was examined by Transwell assays using polyethylene terephthalate membranes (24-well inserts; $8.0 \mu \mathrm{m}$ pore size; Corning, Inc.). A total of $150 \mu 1$ cell suspension containing $1 \times 10^{5}$ cells in FBS-free medium was added to the upper chambers. The lower chambers contained $500 \mu \mathrm{l}$ medium supplemented with $10 \%$ FBS. For the invasion assay, the membrane was pre-coated with $50 \mu 1$ Matrigel $^{\circledR}$ (BD Biosciences) at $37^{\circ} \mathrm{C}$ for $3 \mathrm{~h}$. Cells were maintained in a humidified atmosphere with $5 \% \mathrm{CO}_{2}$ at $37^{\circ} \mathrm{C}$ for $48 \mathrm{~h}$. Cells that had transgressed through the membrane to reach the lower side were fixed with $100 \%$ methanol for $20 \mathrm{~min}$ at room temperature prior to being stained with $0.1 \%$ crystal violet for $10 \mathrm{~min}$ at room temperature. Cells were counted in five randomly selected fields under a light microscope (Olympus Corp.) at x400 magnification.

Statistical analysis. Values are expressed as the mean \pm standard deviation. All experiments were performed in $\geq$ three replicates. Statistical analyses were performed 

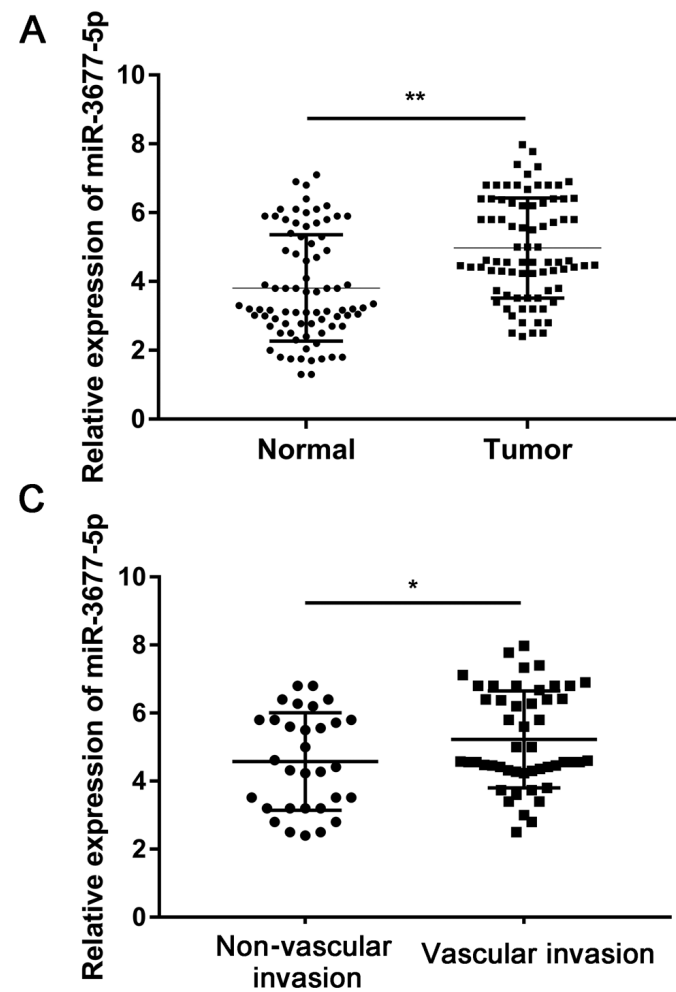

B

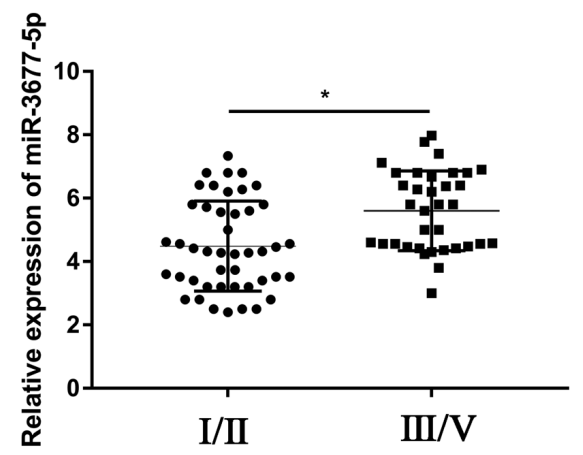

D

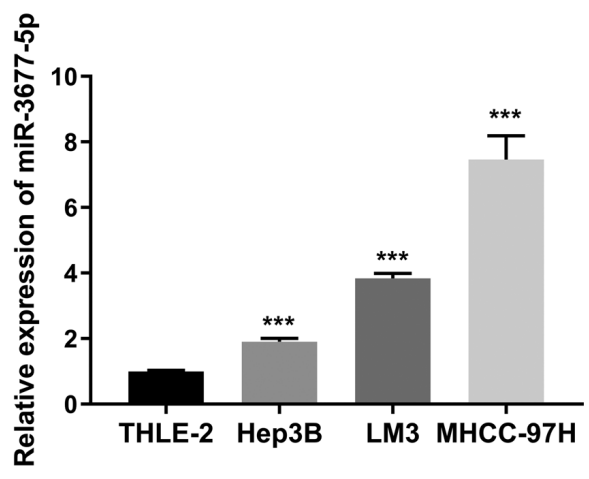

Figure 1. Upregulation of miR-3677-5p expression in HCC tissues and cell lines determined by reverse transcription-quantitative PCR. (A) Relative expression of miR-3677-5p in 80 pairs of tumor tissues and adjacent normal tissues. (B) Relative expression of miR-3677-5p in tumor tissues with TNM stage I/II or III/IV. (C) Relative expression of miR-3677-5p in tumor tissues with or without vascular invasion. (D) Relative expression of miR-3677-5p in three HCC cell lines (Hep3B, LM3 and MHCC-97H) and THLE-2. ${ }^{* * *} \mathrm{P}<0.001$ vs. THLE-2. Values are expressed as the mean \pm standard deviation of three independent experiments. ${ }^{,} \mathrm{P}<0.05,{ }^{* *} \mathrm{P}<0.01,{ }^{* * * *} \mathrm{P}<0.001$. HCC, hepatocellular carcinoma; miR, microRNA.

using GraphPad Prism 5.0 (GraphPad Software, Inc.) and SPSS 20.0 (IBM Corp.). Differences between two groups were analyzed by unpaired Student's t-tests, while the expression of miR-3677-5p in tumor tissues and matched normal tissues was compared using a paired Student's t-test. Comparisons of multiple groups were performed using one-way ANOVA followed by Dunnett's test. Categorical data were compared using a $\chi^{2}$ test. OS and RFS of patients with HCC of patients were evaluated by Kaplan-Meier curves and compared with log-rank tests. Prognostic factors were analyzed by univariate and multivariate logistic regression analysis using the Cox proportional hazards model. $\mathrm{P}<0.05$ was considered to indicate a statistically significant difference.

\section{Results}

miR-3677-5p is upregulated in HCC tissues and cell lines. First, the expression levels of miR-3677-5p in 80 pairs of HCC tissues and paired adjacent normal tissues were determined using RT-qPCR. As presented in Fig. 1A, the expression of miR-3677-5p was significantly elevated in tumor tissues as compared with that in matched normal tissues $(\mathrm{P}<0.01)$. Furthermore, the expression of miR-3677-5p was significantly higher in the tumor tissues of patients with TNM III/V than in those with TNM I/II ( $<<0.05$; Fig. 1B). The expression of miR-3677-5p was significantly higher in the tumor tissues of patients with vascular invasion than in those without vascular invasion $(\mathrm{P}<0.05$; Fig. $1 \mathrm{C})$. In addition, the expression levels of miR-3677-5p were evaluated in several HCC cell lines (Hep3B, LM3 and MHCC-97H) and in the non-cancerous cell line THLE-2. As presented in Fig. 1D, the expression of miR-3677-5p was significantly higher in HCC cell lines than that in THLE-2 cells (all $\mathrm{P}<0.001$ ).

Clinical significance of miR-3677-5p expression in patients with HCC. Next, the association between miR-3677-5p expression and clinicopathologic features was analyzed in patients with HCC. Using the median value of miR-3677-5p expression in HCC tumor tissues being as the cut-off value, patients with HCC were divided into two groups: miR-3677-5p low (below the median, $\mathrm{n}=40$ patients) and miR-3677-5p high (above the median, $\mathrm{n}=40$ patients). As indicated in Table $\mathrm{I}$, the number of patients with $\alpha$-fetoprotein (AFP) $\geq 400 \mathrm{ng} / \mathrm{ml}$ and tumor size $\geq 5 \mathrm{~cm}$ was higher in the high miR-3677-5p expression group than that in the low miR-3677-5p expression group $(\mathrm{P}=0.008$ and 0.026 , respectively). The number of patients with TNM stage III/IV was significantly higher in the high miR-3677-5p expression group $(\mathrm{P}=0.001)$. In addition, patients with vascular invasion were more common in the high miR-3677-5p expression group than in the low miR-3677-5p expression group $(\mathrm{P}=0.012)$. However, there was no significant difference between the two groups in terms of age, sex, hepatitis B surface antigen (HBsAg) status, tumor number and satellite nodules.

The prognostic value of miR-3677-5p in patients with HCC was then investigated. As indicated by Kaplan-Meier curves, patients with high expression of miR-3677-5p in their HCC 
Table I. Association between miR-3677-5p expression and the clinicopathologic features in hepatocellular carcinoma.

\begin{tabular}{|c|c|c|c|c|}
\hline \multirow[b]{2}{*}{ Item } & \multirow[b]{2}{*}{ Total $(n=80)$} & \multicolumn{2}{|c|}{$\operatorname{miR}-3677-5 p$} & \multirow[b]{2}{*}{ P-value } \\
\hline & & Low expression $(n=40)$ & High expression $(n=40)$ & \\
\hline Age (years) & & & & 0.370 \\
\hline$<60$ & 38 & $17(42.5)$ & $21(52.5)$ & \\
\hline$\geq 60$ & 42 & $23(57.5)$ & $19(47.5)$ & \\
\hline Sex & & & & 0.556 \\
\hline Male & 14 & $6(15.0)$ & $8(20.0)$ & \\
\hline Female & 66 & $34(85.0)$ & $32(80.0)$ & \\
\hline HBsAg & & & & 0.390 \\
\hline Negative & 15 & $9(22.5)$ & $6(15.0)$ & \\
\hline Positive & 65 & $31(77.5)$ & $34(85.0)$ & \\
\hline AFP (ng/ml) & & & & 0.008 \\
\hline$<400$ & 25 & $18(45.0)$ & $7(17.5)$ & \\
\hline$\geq 400$ & 55 & $22(55.0)$ & $33(82.5)$ & \\
\hline Tumor number & & & & 0.478 \\
\hline Single & 53 & $28(70.0)$ & $25(62.5)$ & \\
\hline Multiple & 27 & $12(30.0)$ & $15(37.5)$ & \\
\hline Tumor size (cm) & & & & 0.026 \\
\hline$<5$ & 40 & $16(69.6)$ & $7(42.1)$ & \\
\hline$\geq 5$ & 40 & $24(30.4)$ & $33(57.9)$ & \\
\hline Satellite nodules & & & & 0.626 \\
\hline Negative & 56 & $29(72.5)$ & $27(67.5)$ & \\
\hline Positive & 24 & $11(27.5)$ & $13(32.5)$ & \\
\hline TNM stage & & & & 0.001 \\
\hline $\mathrm{I} / \mathrm{II}$ & 45 & $30(75.0)$ & $15(37.5)$ & \\
\hline III/V & 35 & $10(25.0)$ & $25(62.5)$ & \\
\hline Vascular invasion & & & & 0.012 \\
\hline Negative & 31 & $21(52.5)$ & $10(25.0)$ & \\
\hline Positive & 49 & $19(47.5)$ & $30(75.0)$ & \\
\hline
\end{tabular}

Values are expressed as n (\%). HBsAg, hepatitis B surface antigen; AFP, $\alpha$-fetoprotein; TNM, tumor-nodes-metastasis; miR, microRNA.
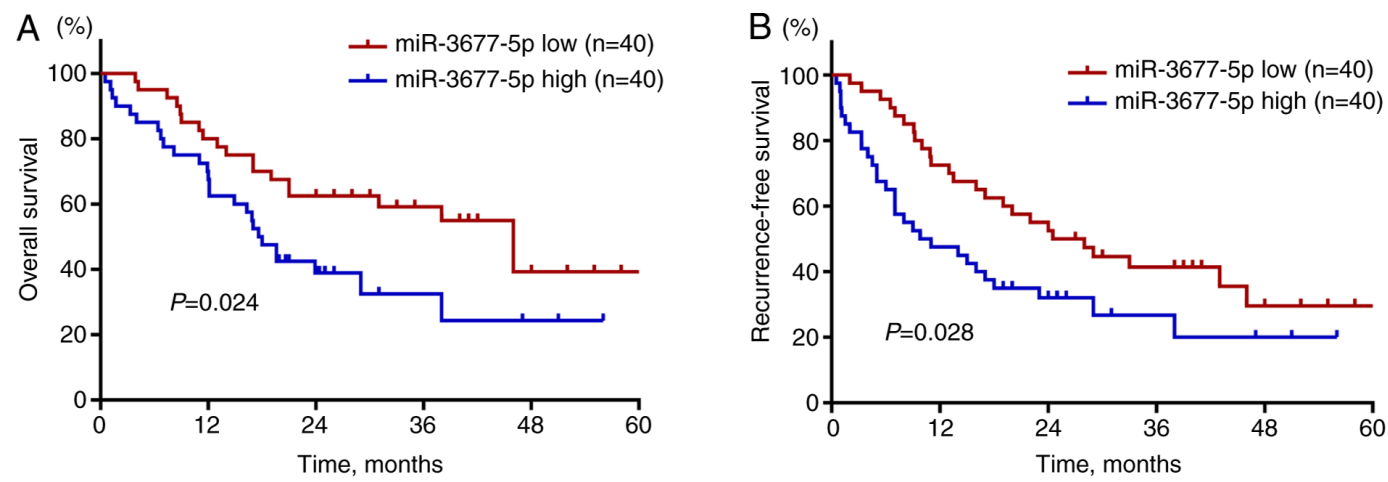

Figure 2. Kaplan-Meier analysis of the influence of miR-3677-5p expression on survival of patients with hepatocellular carcinoma. High expression of miR-3677-5p (miR-3677-5p high, $\mathrm{n}=40$ ) was significantly associated with poor (A) overall survival and (B) recurrence-free survival as compared to low miR-3677-5p expression (miR-3677-5p low, $\mathrm{n}=40$ ). Patients were stratified into the high and low groups using the median miR-3677-5p expression level as a cutoff. miR, microRNA.

tissues were indicated to have poor $\mathrm{OS}(\mathrm{P}=0.024$; Fig. $2 \mathrm{~A})$ and RFS ( $\mathrm{P}=0.028$; Fig. 2B). Next, the prognostic factors affecting OS and RFS were evaluated by multivariate Cox regression analysis. The prognostic factors for OS (Table II) 
Table II. Univariate and multivariate analysis of clinical features influencing overall survival.

\begin{tabular}{|c|c|c|c|c|}
\hline \multirow[b]{2}{*}{ Factor } & \multicolumn{2}{|c|}{ Univariate } & \multicolumn{2}{|c|}{ Multivariate } \\
\hline & $\operatorname{HR}(95 \% \mathrm{CI})$ & P-value & HR $(95 \% \mathrm{CI})$ & P-value \\
\hline Age, $\geq 60$ years & $1.021(0.812-1.191)$ & 0.667 & & \\
\hline Sex, male & $1.008(0.818-1.411)$ & 0.501 & & \\
\hline HBsAg, positive & $1.312(0.901-1.714)$ & 0.091 & & \\
\hline $\mathrm{AFP}, \geq 400 \mathrm{ng} / \mathrm{ml}$ & $1.263(1.113-1.498)$ & 0.001 & $1.221(1.101-1.413)$ & 0.031 \\
\hline Tumor number, multiple & $1.283(0.816-1.964)$ & 0.274 & & \\
\hline Tumor size, $\geq 5 \mathrm{~cm}$ & $1.512(0.912-2.321)$ & 0.012 & & \\
\hline Satellite nodules, positive & $1.612(0.712-2.265)$ & 0.865 & & \\
\hline TNM stage, III/V & $2.248(1.969-2.576)$ & $<0.001$ & $2.119(1.855-2.429)$ & $<0.001$ \\
\hline Vascular invasion, positive & $2.985(2.960-3.014)$ & $<0.001$ & $2.675(2.533-2.764)$ & $<0.001$ \\
\hline miR-3677-5p expression, high & $1.798(1.314-2.579)$ & $<0.001$ & $1.632(1.287-2.015)$ & 0.019 \\
\hline
\end{tabular}

CI, confidence interval; HR, hazard ratio; HBsAg, hepatitis B surface antigen; AFP, $\alpha$-fetoprotein; TNM, tumor-nodes-metastasis; miR, microRNA.

Table III. Univariate and multivariate analysis of clinical features influencing recurrence-free survival.

\begin{tabular}{llrlr}
\hline & \multicolumn{2}{c}{ Univariate } & & Multivariate \\
\cline { 2 - 3 } Factor & HR $(95 \% \mathrm{CI})$ & P-value & & HR (95\% CI) \\
\hline Age, $\geq 60$ years & $1.041(0.856-1.215)$ & 0.312 & \\
Sex, male & $1.011(0.876-1.398)$ & 0.156 & \\
HBsAg, positive & $1.212(0.816-1.651)$ & 0.187 & \\
AFP, $\geq 400$ ng/ml & $1.119(0.876-1.374)$ & 0.056 & \\
Tumor number, multiple & $1.339(0.781-1.816)$ & 0.671 & \\
Tumor size, $\geq 5$ cm & $1.831(0.761-2.879)$ & 0.287 & \\
Satellite nodules, positive & $1.871(0.691-2.995)$ & 1.010 & \\
TNM stage, III/V & $2.345(1.919-2.567)$ & $<0.001$ & \\
Vascular invasion, positive & $2.771(2.461-3.006)$ & $<0.001$ & $2.591(2.391-2.846)$ \\
miR-3677-5p expression, high & $1.910(1.417-2.671)$ & 0.001 & $1.781(1.210-2.337)$ \\
\hline
\end{tabular}

CI, confidence interval; HR, hazard ratio; HBsAg, hepatitis B surface antigen; AFP, a-fetoprotein; TNM, tumor-nodes-metastasis; miR, microRNA.

are summarized as follows: $\mathrm{AFP} \geq 400 \mathrm{ng} / \mathrm{ml}$ [hazard ratio (HR): 1.221, 95\% confidence interval (CI): 1.101-1.413, $\mathrm{P}=0.031]$, TNM stage III/V (HR: 2.119, 95\% CI: 1.885-2.429, $\mathrm{P}<0.001$ ), vascular invasion (HR: $2.675,95 \%$ CI: $2.553-2.764$, $\mathrm{P}<0.001)$ and high expression of miR-3677-5p (HR: 1.632, 95\% CI: $1.287-2.015, \mathrm{P}=0.019)$. The prognostic factors for RFS (Table III) were as follows: TNM stage III/V (HR: 2.101, 95\% CI: $1.801-2.410, \mathrm{P}<0.001$ ), vascular invasion (HR: 2.591 , 95\% CI: 2.391-2.846, P<0.001) and high expression of miR-3677-5p (HR: 1.781, 95\% CI: 1.210-2.337, $\mathrm{P}=0.033$ ). Taken together, the above results suggested that high expression of miR-3677-5p is associated with unfavorable prognosis of patients with HCC.

Overexpression of $m i R-3677-5 p$ promotes the proliferation, migration and invasion of HCC cells. Based on the clinical findings, further experiments were performed to explore the biological functions of miR-3677-5p in the progression of HCC. Using miR-3677-5p mimics, miR-3677-5p was first overexpressed in Hep3B cells; this cell line was chosen because the native cells had a relatively low expression of miR-3677-5p. Significant miR-3677-5p overexpression induced by miR-3677-5p mimics in Hep3B cells was verified by RT-qPCR ( $<<0.001$; Fig. 3A). Subsequent evaluation by a CCK- 8 assay revealed that the OD values for the miR-3677-5p mimics-transfected group of Hep3B cells at 2, 3 and 4 days were significantly higher than those of miR-NC-transfected cells (all $\mathrm{P}<0.01$; Fig. 3B). Next, the crystal violet assay indicated that miR-3677-5p overexpression significantly promoted the proliferation of Hep3B cells $(\mathrm{P}<0.001$; Fig. 3C). In order to explore the effect of miR-3677-5p on the migratory and invasive 
A

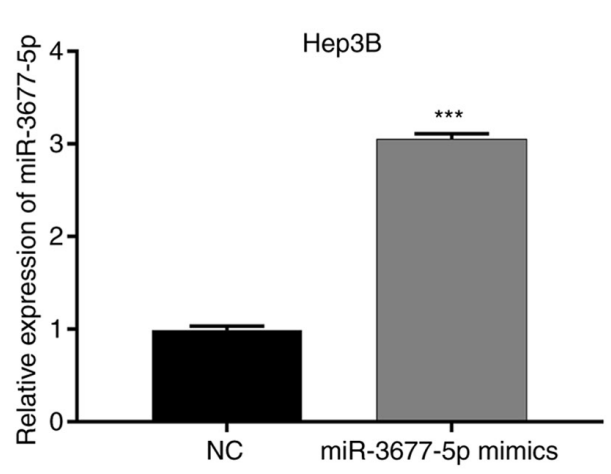

C
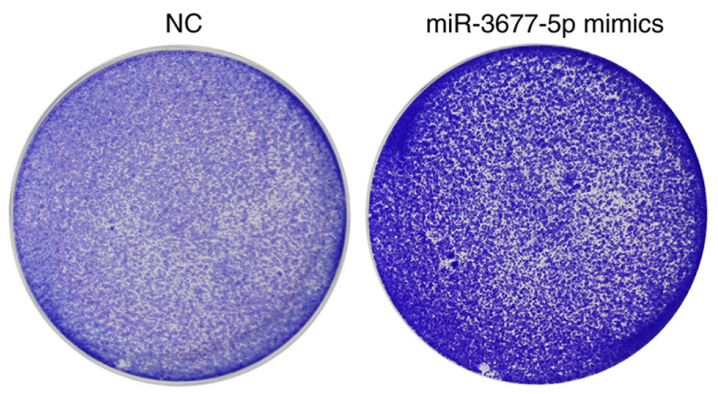

D

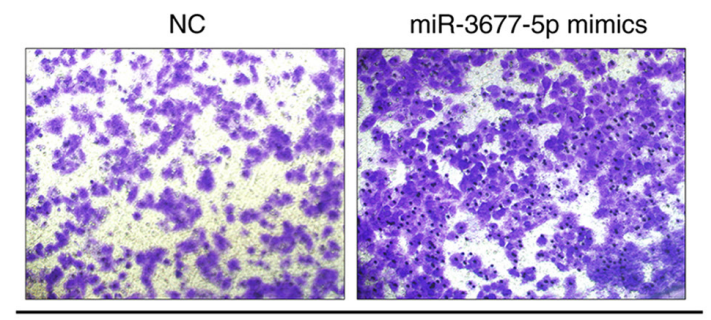

Migration

$\mathrm{E}$

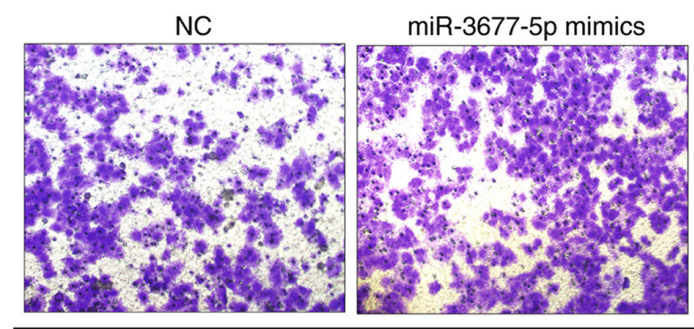

Invasion
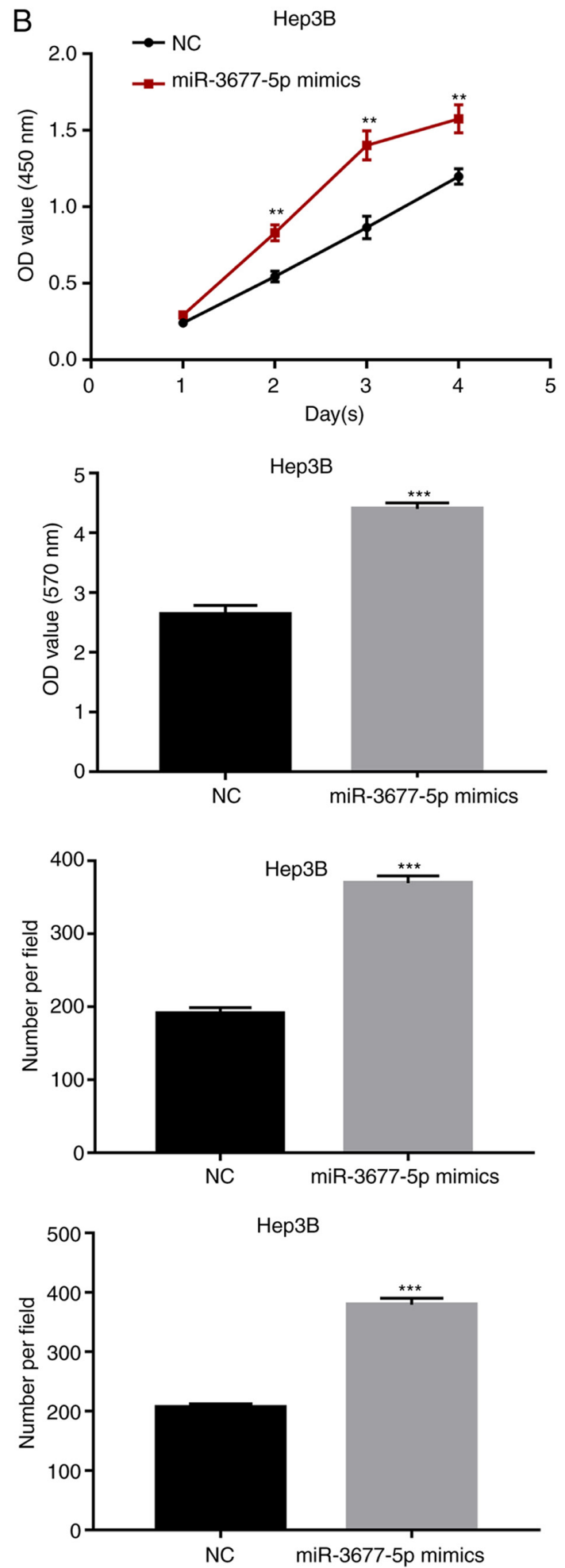

Figure 3. Overexpression of miR-3677-5p promotes the proliferation, migration and invasion capacity of hepatocellular carcinoma cells. (A) Expression of miR-3677-5p in Hep3B cells transfected with miR-3677-5p mimics and NC. (B and C) Effects of miR-3677-5p overexpression on Hep3B cell proliferation assessed by (B) Cell Counting Kit-8 and (C) crystal violet assays. The right-hand panel represents the OD value from the crystal violet assay in C. (D and E) Effects of miR-3677-5p overexpression on Hep3B-cell (D) migration and (E) invasion assessed by Transwell assays (magnification, x400). The right-hand panel presents the quantified number of cells migrated/invaded through the filter following crystal violet staining. Values are expressed as the mean \pm standard deviation of three independent experiments. ${ }^{* * *} \mathrm{P}<0.01,{ }^{* * * *} \mathrm{P}<0.001$. miR, microRNA; NC, negative control; OD, optical density.

capacities of Hep3B cells, Transwell assays were performed. As presented in Fig. 3D and E, miR-3677-5p overexpression significantly promoted the migration and invasion of Hep3B cells (all $\mathrm{P}<0.001)$.
Knockdown of miR-3677-5p inhibits the proliferation, migration and invasion of HCC cells. miR-3677-5p inhibitor was further used to knock down the expression of miR-3677-5p in MHCC-97H cells. This cell line was chosen as the native 
A

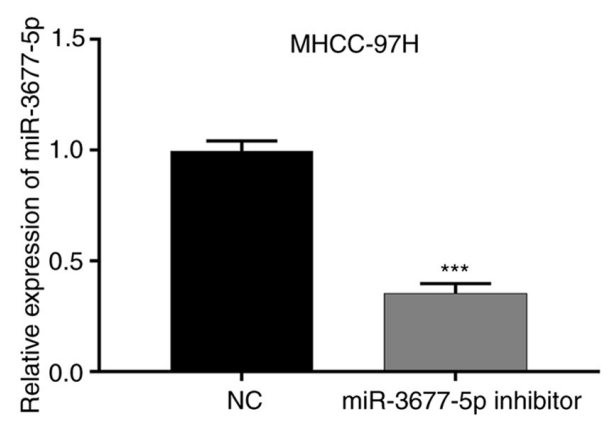

C
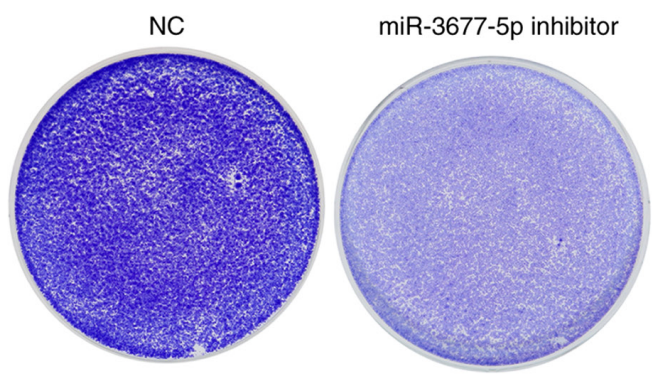

$\mathrm{D}$

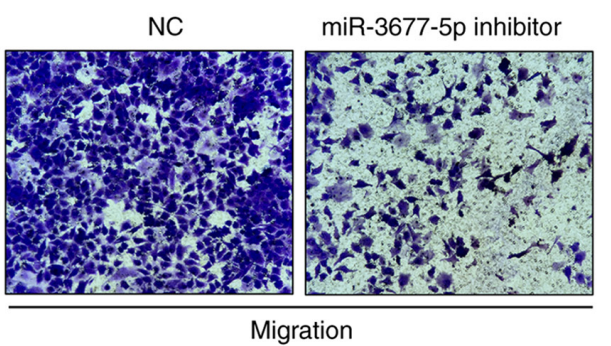

E

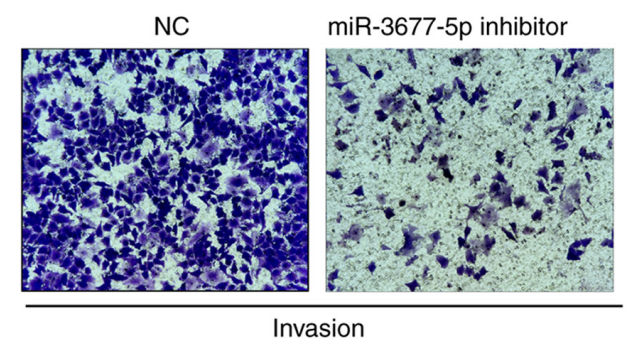

B
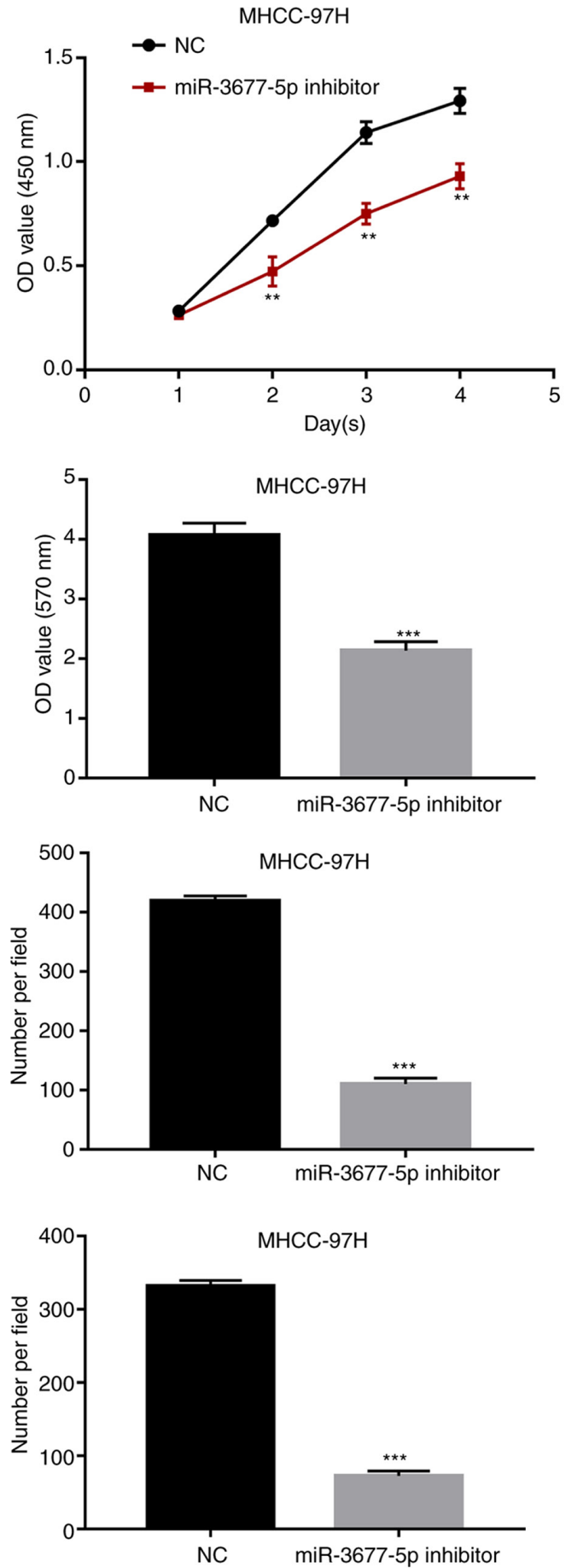

Figure 4. Knockdown of miR-3677-5p inhibits the proliferation, migration and invasion capacity of HCC cells. (A) Expression of miR-3677-5p in MHCC-97H cells transfected with miR-3677-5p inhibitor and NC. (B and C) Effects of miR-3677-5p knockdown on MHCC-97H cell proliferation assessed by (B) Cell Counting Kit-8 (C) and crystal violet assays. The right-hand panel represents the OD value from crystal violet assay in C. (D and E) Effects of miR-3677-5p knockdown on MHCC-97H-cell (D) migration and (E) invasion assessed by Transwell assays (magnification, x400). The right-hand panel presents the quantified number of cells migrated/invaded through the filter following crystal violet staining. Values are expressed as the mean \pm standard deviation of three independent experiments. ${ }^{* *} \mathrm{P}<0.01,{ }^{* * *} \mathrm{P}<0.001$. miR, microRNA; NC, negative control; OD, optical density.

cells exhibited relatively high expression of miR-3677-5p. The knockdown efficacy was confirmed by RT-qPCR $(\mathrm{P}<0.001$; Fig. 4A). Next, evaluation by CCK-8 and crystal violet assays indicated that miR-3677-5p downregulation significantly inhibited the proliferation of MHCC-97H cells (all $\mathrm{P}<0.01$; Fig. 4B and C). In addition, analysis by Transwell assays indicated a significantly decreased cell migratory and invasive capacity of miR-3677-5p inhibitor-transfected MHCC-97H cells compared with that in cells from the NC group (all $\mathrm{P}<0.001$; Fig. 4D and E).

\section{Discussion}

To date, a variety of miRNAs that exert fundamental roles in the progression of HCC have been proposed as promising prognostic predictors (19). For instance, Budhu et al (20) 
have reported a 20-miRNA metastasis signature capable of predicting $\mathrm{HCC}$ with vascular metastases that is associated with patient survival. It has also been demonstrated that the combination of miR-10b, miR-106b and miR-181a is able to discriminate patients with HCC from normal controls (21). In addition, miRNAs have been reported to function as oncogenes or tumor suppressors in the regulation of fundamental biological processes, such as cell proliferation, migration and invasion, of HCC cells (22). Xie et al (23) demonstrated that miR-6875-3p promotes the proliferation, invasion and metastasis of HCC cells. Consistently, You et al (24) reported that ectopic miR-766-3p expression inhibits HCC cell proliferation, colony formation, migration and invasion.

Previously, the functions of miR-3677 in tumorigenesis were poorly understood. Zhang et al (12) have generated a 7-miRNA signature in patients with HCC based on The Cancer Genome Atlas database, in which miR-3677 has been identified as one of the significant miRNAs that are able predict poor survival of patients with HCC. In agreement with this, Lu et al (14) also reported that miR-3677 is significantly associated with survival of patients with HCC. Through microarray analysis, Żorniak et al (25) determined that miR-3667 is highly expressed in cirrhotic patients with gastric antral vascular ectasia. miR-3677 has also been identified as a key oncogenic miRNA in breast cancer and significant differences in prognosis were obtained when stratifying patients into high-risk and low-risk groups (26). Furthermore, Peng et al (27) revealed that overexpression of miR-3677 promoted the proliferation, migration and invasion of breast cancer cells. Recently, Yao et al (28) reported that $\mathrm{miR}-3677-3 \mathrm{p}$ overexpression promoted the malignant behavior and invasiveness of HCC via suppression of sirtuin 5. Another study that determined the oncogenic role of miR-3677-3p in HCC indicated that knockdown of miR-3677-3p inhibited the proliferation of HCC cells via directly targeting the 3'untranslated region of glycogen synthase kinase 3- $\beta$ (29).

In the present study, it was determined that miR-3677-5p expression was upregulated in human HCC tissues and cell lines compared with that in adjacent normal tissues and a non-cancerous liver cell line, respectively. Furthermore, it was demonstrated that the expression of miR-3677-5p is closely associated with AFP, tumor size, TNM stage and vascular invasion. Of note, high miR-3677-5p expression was indicated to be capable of predicting unfavorable clinical prognosis in patients with HCC. These results demonstrated the prognostic value, as well as the oncogenic role of miR-3677-5p in HCC. Subsequently, a functional in vitro study was performed and miR-3677-5p was overexpressed or knocked down in two HCC cell lines using miR-3677-5p mimics or inhibitor, respectively. Subsequently, the effects of miR-3677-5p on cell proliferation, migration and invasion were investigated. The results suggested that miR-3677-5p overexpression promoted the proliferation, migration and invasion of HCC cells. Conversely, miR-3677-5p knockdown resulted in an inhibitory effect. To the best of our knowledge, the present study was the first to determine the biological roles of miR-3677-5p in HCC and its progression, as well as its prognostic value. However, the present study remains preliminary and the clinical application of miR-3677-5p and the mechanisms of how it promotes the progression of HCC cells have yet to be established. Further studies that focus on the identification of direct target genes of miR-3677-5p, as well as the underlying regulatory mechanisms, are required. In addition, animal models may be used to validate the functions of miR-3677-3p in vivo (30).

In conclusion, the present study demonstrated that miR-3677-5p acts as an oncogene and has a critical role in the regulation of HCC cell proliferation and progression. The present results indicated that miR-3677-5p may be a valuable prognostic biomarker and may facilitate the development of a promising treatment strategy for patients with HCC.

\section{Acknowledgements}

Not applicable.

\section{Funding}

No funding was received.

\section{Availability of data and materials}

The datasets used and/or analyzed during the current study are available from the corresponding author on reasonable request.

\section{Authors' contributions}

HXM, KJQ and BYC designed the study and performed the experiments. JW, CYM and YCG collected the clinical samples and analyzed the data. All authors read and approved the final version of the manuscript. HXM and KJQ checked and approved the authenticity of the raw data.

\section{Ethics approval and consent to participate}

All included patients provided written informed consent. The present study was approved by the ethics committee of the Ningbo Medical Treatment Center Li Huili Hospital (Ningbo, China) and was conducted in accordance with the Declaration of Helsinki.

\section{Patient consent for publication}

Not applicable.

\section{Competing interests}

The authors declare that they have no competing interests.

\section{References}

1. Lu XJ, Shi Y, Chen JL and Ma S: Kruppel-like factors in hepatocellular carcinoma. Tumour Biol 36: 533-541, 2015.

2. Yu WB, Rao A, Vu V, Xu L, Rao JY and Wu JX: Management of centrally located hepatocellular carcinoma: Update 2016. World J Hepatol 9: 627-634, 2017.

3. Portolani N, Coniglio A, Ghidoni S, Giovanelli M, Benetti A, Tiberio GA and Giulini SM: Early and late recurrence after liver resection for hepatocellular carcinoma: Prognostic and therapeutic implications. Ann Surg 243: 229-235, 2006.

4. Hu J and Gao DZ: Distinction immune genes of hepatitis-induced heptatocellular carcinoma. Bioinformatics 28: 3191-3194, 2012.

5. Marquardt JU, Galle PR and Teufel A: Molecular diagnosis and therapy of hepatocellular carcinoma (HCC): An emerging field for advanced technologies. J Hepatol 56: 267-275, 2012. 
6. Tutar Y: miRNA and cancer; computational and experimental approaches. Curr Pharm Biotechnol 15: 429, 2014.

7. Qadir MI and Faheem A: miRNA: A diagnostic and therapeutic tool for pancreatic cancer. Crit Rev Eukaryot Gene Expr 27: 197-204, 2017

8. Sun Z, Shi K, Yang S, Liu J, Zhou Q, Wang G, Song J, Li Z, Zhang Z and Yuan W: Effect of exosomal miRNA on cancer biology and clinical applications. Mol Cancer 17: 147, 2018.

9. Sartorius K, Sartorius B, Winkler C, Chuturgoon A and Makarova J: The biological and diagnostic role of miRNA's in hepatocellular carcinoma. Front Biosci (Landmark Ed) 23 $1701-1720,2018$

10. Mao B and Wang G: MicroRNAs involved with hepatocellular carcinoma (Review). Oncol Rep 34: 2811-2820, 2015.

11. He S, Zhang DC and Wei C: MicroRNAs as biomarkers for hepatocellular carcinoma diagnosis and prognosis. Clin Res Hepatol Gastroenterol 39: 426-434, 2015.

12. Zhang J, Chong CC, Chen GG and Lai PB: A Seven-microRNA expression signature predicts survival in hepatocellular carcinoma. PLoS One 10: e0128628, 2015.

13. Qin L, Huang J, Wang G, Huang J, Wu X, Li J, Yi W, Qin F and Huang D: Integrated analysis of clinical significance and functional involvement of microRNAs in hepatocellular carcinoma. J Cell Physiol 234: 23581-2395, 2019.

14. Lu M, Kong X, Wang H, Huang G, Ye C and He Z: A novel microRNAs expression signature for hepatocellular carcinoma diagnosis and prognosis. Oncotarget 8: 8775-8784, 2017.

15. Nagy A, Lanczky A, Menyhart O and Gyorffy B: Validation of miRNA prognostic power in hepatocellular carcinoma using expression data of independent datasets. Sci Rep 8: 9227, 2018.

16. Chen W, Gao C, Liu Y, Wen Y, Hong X and Huang Z: Bioinformatics analysis of prognostic miRNA signature and potential critical genes in colon cancer. Front Genet 11: 478 , 2020.

17. Zhang H, Wang Z, Ma R, Wu J and Feng J: MicroRNAs as biomarkers for the progression and prognosis of colon carcinoma. Int J Mol Med 42: 2080-2088, 2018.

18. Livak KJ and Schmittgen TD: Analysis of relative gene expression data using real-time quantitative PCR and the 2(-Delta Delta C(T)) method. Methods 25: 402-408, 2001

19. Villanueva A, Hoshida Y, Toffanin S, Lachenmayer A, Alsinet C, Savic R, Cornella H and Llovet JM: New strategies in hepatocellular carcinoma: Genomic prognostic markers. Clin Cancer Res 16: 4688-4694, 2010.

20. Budhu A, Jia HL, Forgues M, Liu CG, Goldstein D, Lam A, Zanetti KA, Ye QH, Qin LX, Croce CM, et al: Identification of metastasis-related microRNAs in hepatocellular carcinoma. Hepatology 47: 897-907, 2008
21. Jiang L, Cheng Q, Zhang BH and Zhang MZ: Circulating microRNAs as biomarkers in hepatocellular carcinoma screening: A validation set from China. Medicine (Baltimore) 94: e603, 2015.

22. Petrini E, Caviglia GP, Abate ML, Fagoonee S, Smedile A and Pellicano R: MicroRNAs in HBV-related hepatocellular carcinoma: Functions and potential clinical applications. Panminerva Med 57: 201-209, 2015.

23. Xie Y, Du J, Liu Z, Zhang D, Yao X and Yang Y: miR-6875-3p promotes the proliferation, invasion and metastasis of hepatocellular carcinoma via BTG2/FAK/Akt pathway. J Exp Clin Cancer Res 38: 7, 2019

24. You Y, Que K, Zhou Y, Zhang Z, Zhao X, Gong J and Liu Z MicroRNA-766-3p inhibits tumour progression by targeting Wnt3a in hepatocellular carcinoma. Mol Cells 41: 830-841, 2018.

25. Żorniak M, Garczorz W, Wosiewicz P, Marek T, Błaszczyńska M, Waluga M, Kukla M, Kimsa-Furdzik M, Francuz T and Hartleb M: Mucosal miR-3677 is over-expressed in cirrhotic patients with gastric antral vascular ectasia (GAVE). Scand J Gastroenterol 53: 1503-1508, 2018.

26. Lu DC, Han W and Lu K: Identification of key microRNAs involved in tumorigenesis and prognostic microRNAs in breast cancer. Math Biosci Eng 17: 2923-2935, 2020.

27. Peng LN, Deng XY, Gan XX, Zhang JH, Ren GH, Shen F, Feng JH, Cai WS and Xu B: Targeting of TLE3 by miR-3677 in human breast cancer promotes cell proliferation, migration and invasion. Oncol Lett 19: 1409-1417, 2020.

28. Yao B, Li Y, Niu Y, Wang L, Chen T, Guo C and Liu Q: Hypoxia-induced miR-3677-3p promotes the proliferation, migration and invasion of hepatocellular carcinoma cells by suppressing SIRT5. J Cell Mol Med 24: 8718-8731, 2020.

29. Li Y, Zhou Y, Ma L, Liu D, Dai Z and Shen J: miR-3677-3p promotes hepatocellular carcinoma progression via inhibiting GSK3 $\beta$. Acta Biochim Biophys Sin (Shanghai) 52: 1404-1412, 2020.

30. Robinson NB, Krieger K, Khan FM, Huffman W, Chang M, Naik A, Yongle R, Hameed I, Krieger K, Girardi LN and Gaudino M: The current state of animal models in research: A review. Int J Surg 72: 9-13, 2019.

This work is licensed under a Creative Commons Attribution-NonCommercial-NoDerivatives 4.0 International (CC BY-NC-ND 4.0) License. 